\title{
UMA AVALIAÇÃO FEITA POR LICENCIANDOS SOBRE ATIVIDADES INVESTIGATIVA-EXPLORATÓRIAS DE MATEMÁTICA FINANCEIRA
}

\section{AN ASSESSMENT BY GRADUATES ON INVESTIGATIVE-EXPLORATORY ACTIVITIES OF FINANCIAL MATHEMATICS}

\author{
Rafael Filipe Novôa Vaz ${ }^{1}$ \\ Marco Aurélio Kistemann Junior ${ }^{2}$
}

\begin{abstract}
Resumo: O presente artigo objetiva apresentar as ações e produções de licenciandos em Matemática, numa avaliação com atividades investigativo-exploratórias envolvendo conteúdos e temáticas da Matemática Financeira. A fundamentação teórica foi realizada em Kistemann Jr. no tocante à Educação Financeira e Ensino de Matemática Financeira, Skovsmose na temática da Educação Matemática Crítica e Cenários para Investigação e Zigmunt Bauman que problematiza a sociedade de consumo líquido-moderna. Como principal resultado da prática realizada destacamos a participação dos estudantes e as reflexões efetuadas nas situações envolvendo temas cotidianos da realidade econômica que os cerca e que, em geral passa desapercebido dos indivíduos-consumidores
\end{abstract}

Palavras-chave: Educação Financeira; Matemática Financeira; Cenários para Investigação.

\begin{abstract}
This article aims to present the actions and student's productions in mathematics, an assessment with investigative activities-involving content and thematic exploration of financial mathematics. The theoretical foundation was held in Kistemann Jr. regarding financial education and teaching financial mathematics, Mathematical Education in Skovsmose and scenarios for investigation and Zigmunt Bauman that discusses society of consumption liquid-modern. As a main result of practice held the participation of students and the reflections made in situations involving everyday themes of economic reality around them and that generally passes unnoticed of individuals-consumers.
\end{abstract}

Keywords: Financial Education; Financial Mathematics; Scenarios for Investigation.

\section{Introdução}

Há uma concepção de ensino de Matemática Financeira predominante há alguns anos, ainda recorrente nos dias atuais, que relaciona a aprendizagem de matemática financeira (em contexto escolar e/ou acadêmico) ao domínio de fórmulas, cálculos de juros simples e compostos (na educação básica) e montagem planilhas de sistemas de amortização (no ensino superior). Nessa perspectiva, a matemática financeira é concebida

\footnotetext{
${ }^{1}$ Doutorando PEMAT/UFRJ. Professor do Instituto Federal do Rio de Janeiro (IFRJ), Paracambi, RJ, Brasil. E-mail: rafael.vaz@ifrj.edu.br

2 Doutor em Educação Matemática pela Universidade Estadual Paulista (UNESP). Pesquisador do Departamento de Matemática-Pesquisa de Ponta (UFJF), Juiz de Fora, MG, Brasil. E-mail: marco.kistemann@ufjf.edu.br
} 
DOI: http://dx.doi.org/10.33238/ReBECEM.2019.v.3.n.2.22629

como o domínio de técnicas para a utilização de fórmulas "engessadas" que podem ter, ou não, alguma conexão com a realidade. Obviamente, aprender a utilizar uma fórmula do cálculo do montante ou construir uma planilha do Sistema Price é importante e faz parte da formação financeira que todos os estudantes têm direito, mas talvez isso não seja suficiente, pois esta perspectiva reduz o potencial da matemática financeira em questões próprias e interdisciplinares, como por exemplo, a tomada de decisão em relação ao consumo, a inflação e os parcelamentos "sem juros" praticados pelo mercado. São diversas situações em que os professores podem explorar de forma aplicada a matemática financeira proporcionando benefícios aos estudantes.

A Educação Financeira desponta como a maior novidade na Base Nacional Comum Curricular (BNCC). Em pesquisas levantadas na dissertação de Almeida (2015) observa-se um crescente movimento de pesquisas a abordar uma eduação para o consumo, ou uma educação que se utiliza de conteúdos de Matemática Financeira para a tomada de decisão, ou pesquisas que esclarecem que a Matemática Financeira é um instrumento que pode auxiliar na educação financeira da população. Também há investigações que revelam uma preocupação com os vieses políticos e sociológicos da Educação Financeira e práticas escolares (ALMEIDA, 2015).

De qualquer forma, a Matemática Financeira não é Educação Financeira, bem como a Educação Financeira não ocorre somente com a aprendizagem de conteúdos de Matemática Financeira e a crise econômica de 2008 é um bom exemplo, uma vez que capacitados economistas conhecedores de tópicos de macro e microeconomia e de econometria não conseguiram prever a crise do subprime. Contudo, muitas pesquisas ainda giram e não esclarecem tal fato.

Matemática Financeira é um conjunto de conhecimentos, conceitos e algoritmos que os professores problematizam em suas aulas buscando resolver problemas de Matemática com foco em finanças, juros, capitalização, etc. É uma ferramenta que pode compor a Educação Financeira de um indivíduo-consumidor, de acordo com os autores desse artigo. As aulas de matemática financeira carecem de abordagens que incentivem aos estudantes, os trabalhadores do futuro, e em alguns casos do presente, a realizar aplicações em fundos de investimentos, em renda fixa e no tesouro direto. As aulas ainda estão incipientes na discussão sobre temas econômicos como o câmbio, a inflação, as taxas de juros básicos da economia, bem como na conexão entre consumo, preço dos produtos com a lei da oferta e da demanda tão importante para guiar o consumidor em momentos de crise e recessão na economia. Ainda são poucas as pesquisas que abordem 
DOI: http://dx.doi.org/10.33238/ReBECEM.2019.v.3.n.2.22629

ainda a sustentabilidade, o empreendedorismo social e sustentável e temas relativos à temática ecológica.

A sociedade líquido-moderna, termo cunhado pelo sociólogo Zygmunt Bauman, que associa, individualmente, o consumo a felicidade, e associa, coletivamente, as vendas ao sucesso da economia, oferece ofertas sedutoras do tipo: "Leve 4 e Pague 3 'ou "tudo em 3 parcelas, sem juros", "SÒ HOJE!!!”, “50\% OFF” e a "Black Friday”, que oferece, comumente no caso brasileiro descontos após a realização de aumentos. As ofertas relacionadas a "tudo pela metade do dobro" configuram-se nesse caso em "black fraudes".

A Educação Financeira é uma área dinâmica na sociedade líquido-moderna de consumo que deve ser efetuado de forma processual, em cenários para investigação como proposto por Ole Skovsmose, não somente em ambientes escolares, mas onde for necessário. Isto para que o povo seja educado a partir de um letramento financeiro que o permita tomar decisões-micro em suas ações domésticas com a organização de suas contas, bem como tomar decisões-macro, investigando que decisões deve tomar ao contratar um empréstimo, financiar um bem, votar no candidato que apresenta uma melhor previdência para a aposentadoria de seu povo, agir de forma empreendedora e sustentável no meio em que se insere.

É nítida as diferenças entre a Educação Financeira e a Matemática Financeira, contudo, muitos ainda confundem suas potencialidades e as reduzem a uma só área ou termo. A primeira pode contemplar a segunda e deve, de forma que os indivíduosconsumidores seja capazes de ler, interpretar e tomar decisões a partir da segunda. Satisfeitos com suas decisões éticas tomadas, os indivíduos-consumidores seguirão incrementando, gradativamente, a sua literacia financeira ou matemacia financeira.

\section{Educação Financeira Escolar na sociedade do consumo}

Para Silva (2014), a cultura consumista está profundamente enraizada em nosso comportamento diário de forma, frequentemente, imperceptível. A felicidade torna-se uma mercadoria, pode ser comprada e forma parcelada. Segundo essa autora, as últimas três décadas de transição do século XX para o século XXI são caracterizadas pela era do esplendor da economia de mercado. Seus princípios e valores passaram a dominar nossa vida como jamais ocorreu. No entanto, há um problema gerado por essa nova gestão econômica, pois

os valores de mercado deixaram de ser restritos aos aspectos de economia de compra e venda de bens materiais; eles passaram a governar, de forma 
DOI: http://dx.doi.org/10.33238/ReBECEM.2019.v.3.n.2.22629

crescente e imperialista, nossa vida como um todo, inclusive ditando a maneira como pensamos e agimos na sociedade (SILVA, 2014, p. 185).

De acordo com Bauman, a soma total das atividades de compra da nação é a medida fundamental e menos falível de ventura da sociedade e no plano individual, a completude do consumidor significa completude da vida. Esse importante pensador associa o nosso comportamento consumista ao narcisismo crescente presente na sociedade e incentivado pela mídia e pelo governo. Bauman, relata um inusitado e marcante fato, que exemplifica a sociedade "doente" que vivemos, o então presidente dos EUA, G. W. Bush, no dia seguinte ao atentado das torres gêmeas, clamou aos americanos que superassem o trauma e voltassem as compras. "A mensagem não poderia ser mais clara, o caminho da felicidade passa pelas compras" (BAUMAN, 2015, p. 61).

Que tipo de educação financeira escolar pode melhor contribuir para a formação de cidadãos para essa sociedade de consumo líquido-moderna? Como problematizar a matemática financeira para contribuir na formação crítica dos indivíduos-consumidores?

Diversos pesquisadores (D’AMBRÓSIO, 2016; KISTEMAN JR., 2014; LIMA; SÁ, 2010; SKOVSMOSE, 2014) defendem que as aulas de matemática financeira devem fornecer subsídios para a tomada de decisão para transcender a aplicação de fórmulas. Questões descontextualizadas e isentas de aplicabilidade em situações práticas não contribuem para a formação de um cidadão economicamente consciente. Na perspectiva crítica adotada por esses autores, não há neutralidade no ensino de matemática. Ensinar matemática é uma forma de atuação na sociedade, assim,

$\mathrm{Na}$ sociedade capitalista em que vivemos, o ensino e a aprendizagem é composta de práticas de ensino de matemática permeadas pela prejudicial neutralidade científica e ensino de objetos matemáticos obsoletos, incrementam a distância entre os indivíduos eleitos socialmente e os indivíduos que jazem em situações de pobreza e exclusão (KISTEMAN JR., 2014, p.146).

Skovsmose (2013), defende que a alfabetização matemática tenha como propósito o empowerment, que enraizada em um espírito de crítica permita que as pessoas participem "no entendimento e na transformação de suas sociedades" sendo, nesse contexto, "um pré-requisito para a emancipação social" (p. 67). O empowerment "não está conectado a alguma habilidade isolada de efetuar cálculos matemáticos como tal, mas a um entendimento de como a matemática é aplicada e usada" (p. 95). Nesse sentido,

A educação econômica e financeira pode preparar os estudantes para situações de tomada de decisão. Ao fazê-lo, a racionalidade é a característica central de se fazer decisões econômicas. Racionalidade neste contexto significa a capacidade de selecionar o melhor dentre as alternativas disponíveis, do ponto de vista individual (LOERWALD; STEMMANN, 2016, p. 27, tradução nossa). 
Muniz e Jurkiewicz (2016) defendem a utilização de quatro princípios na Educação Financeira Escolar: convite à reflexão, conexão didática, dualidade e lente multidisciplinar. O convite à reflexão consiste em "oferecer aos estudantes a oportunidade de reflexão através da leitura de situações financeiras que contemplem diferentes aspectos (...), para que pensem, avaliem e tomem suas próprias decisões" (p.121). Não se trata alerta os autores de um doutrinamento financeiro, os estudantes devem ler criticamente com autonomia, pois "o que pode ser ótimo do ponto de vista econômico pode ser a pior opção do ponto de vista psicológico, ou cultural” (p.121).

O princípio da conexão didática é aquele que diferencia a educação financeira escolar da "educação financeira" promovida pelos bancos, "na medida em que se volta para as questões de ensino e aprendizagem de matemática (inclusive), sem desconsiderar os diversos contextos e comportamentos presentes na sociedade" (p.121).

A dualidade consiste no duplo benefício em que, por um lado, a Educação Financeira Escolar pode receber em "entender, analisar e tomar decisões em situações financeiras" (p.122) sob um ponto de vista matemático e, no caminho inverso, as situações financeiras podem ser usadas para aprender matemática.

Muniz e Jurkiewicz (2016) defendem ainda que a matemática financeira seja ensinada em diálogo com outras áreas do conhecimento, utilizando o viés multidisciplinar que possibilitará

\begin{abstract}
oferecer múltiplas leituras sobre as situações financeiras. Aspectos financeiros, matemáticos, comportamentais, culturais, biológicos, políticos e ecológicos podem ser utilizados de forma articulada para ajudar os estudantes na leitura de situações de consumo, renda, endividamento, investimento, planejamento financeiro, sustentabilidade, dentre outras. Estudos do Marketing, da Neurociência, da Economia, da Antropologia e Sociologia do Consumo se constituem em diferentes lentes. E como lentes, focam alguns aspectos e desfocam outros (MUNIZ; JURKIEWICZ, 2016, p. 122).
\end{abstract}

\title{
3 Atividades investigativas-exploratórias de matemática financeira
}

Nos livros didáticos, por exemplo, é comum encontrar questões que envolvam o cálculo, por exemplo, do montante a ser pago por um empréstimo em cota única, meses depois sob regime de capitalização simples. Essas questões deveriam ser questionadas pelos professores...

- Qual banco realiza um empréstimo deste tipo a juros simples?

- É comum realizar um empréstimo que deverá ser quitado em um pagamento meses depois? 
DOI: http://dx.doi.org/10.33238/ReBECEM.2019.v.3.n.2.22629

Questões como essa, desconectadas da realidade econômica, perdem sua possível função pedagógica de introdução de conceito ao serem utilizadas de modo predominante nas aulas. Quando diversas questões como essa, compõem listas de exercícios repetitivos, obtêm-se, possivelmente, um efeito cognitivo mais relacionado à memorização de fórmulas e procedimentos ao invés da promoção de reflexões e reflexões com relação às atitudes que um cidadão se utiliza para administrar seu dinheiro, para comprar, investir e para pagar seus impostos.

Skovsmose (2014), citando o estudo de Cotton (1998), aponta para existência de um formato padrão nas aulas de matemática: expositiva, composta de uma explicação teórica, amparada em alguns exemplos e uma bateria de exercícios que serão corrigidos em um momento final. Skovsmose denominou esse formato adotado nas aulas de matemática como paradigma do exercício. Nesse contexto,

o livro didáctico representa as condições tradicionais da prática de sala de aula. Os exercícios são formulados por uma autoridade externa à sala de aula. Isso significa que a justificação da relevância dos exercícios não é parte da aula de matemática em si mesma. Além disso, a premissa central do paradigma do exercício é que existe uma, e somente uma, resposta correta (SKOVSMOSE, 2000, p.1).

Em uma perspectiva oposta, as questões de matemática podem ser confeccionadas com um perfil reflexivo e crítico. Um exemplo é a questão proposta por Kistemann Jr. e Campos (2014, p.1001):

Um casal de indivíduos-consumidores poupa há alguns anos todo mês a quantia de $\mathrm{R} \$ 100,00$ na poupança a fim de garantir o futuro de seu único filho quando este atingir a maioridade. Num dado mês do ano (mês de férias da família) descobrem ao retirar um extrato bancário que gastaram $\mathrm{R} \$ 1000,00 \mathrm{a}$ mais no cartão de crédito, isto é, estão com um saldo negativo em sua conta de $\mathrm{R} \$ 1000,00$ não possuindo reservas pessoais para quitar esse valor.

a) Possuindo cheque especial, cartão de crédito, crédito na praça, que decisão deve tomar o casal para quitar esse valor a mais que apareceu em seu extrato bancário?

b) O casal de indivíduos consumidores, em virtude de não possuírem reservas, decide utilizar o cheque especial para quitar esses $\mathrm{R} \$ 1000,00$. O que você acha dessa decisão?

Essa questão nos possibilita duas reflexões pertinentes, a primeira em relação ao seu caráter social e a segunda em relação ao seu caráter pedagógico.

(i) A matemática fornecida nesse exemplo está conectada com a vida das pessoas, em uma situação muito comum aos brasileiros. Além de conectar a realidade, questões assim podem oferecer contribuições para promoção de mais justiça social. Nomenclaturas como cartão de crédito, cheque especial, extratos bancários e crédito talvez não sejam tão 
DOI: http://dx.doi.org/10.33238/ReBECEM.2019.v.3.n.2.22629

comuns às crianças pertencentes às classes sociais mais desfavorecidas. Como então, irão aprender sobre os perigos da utilização do cartão de crédito?

(ii) Essa questão pode suscitar debates interessantes em sala de aula e guiar a turma para a realização de pequenas investigações: “o que é o cheque especial?”, “qual é a taxa de juros cobrado do cheque especial?" e "qual é a taxa de juros da poupança”? Pedagogicamente, pode ser utilizada para a realização de um trabalho em grupo ou de uma pesquisa. O professor de matemática pode substituir o formato padrão da sala de aula, enfileirados, para uma roda de discussão ou pequenas rodas ao redor de uma mesa. Entretanto, o professor se coloca em um novo ambiente de incertezas. Há um risco maior de não saber a reposta a uma pergunta inesperada, de não conseguir "controlar a turma" mantendo-a em silêncio. Aliás, essas não seriam falhas do professor falhas, necessariamente, e sim características de uma atividade deste tipo.

Barbosa (2001, p.5), defende que propor atividades investigativas, denominadas de modelagem matemática em sala de aula, pode contribuir para a aprendizagem dos estudantes pois oferece "uma oportunidade para os alunos indagarem situações por meio da matemática sem procedimentos fixados previamente e com possibilidades diversas de encaminhamento". Nas palavras do autor, a "modelagem é um ambiente de aprendizagem no qual os alunos são convidados a indagar e/ou investigar, por meio da matemática, situações oriundas de outras áreas da realidade"

Skovsmose (2000), Alro e Skovsmose (2010), propõem a substituição das aulas tradicionais (vinculadas ao paradigma do exercício) por um ambiente investigativo. Aula tradicional para Skovsmose não se restringe aos aspectos negativos e estereotipados, no qual o professor tiraniza alunos, mas sim no formato em que o livro texto ocupa o papel central, o professor traz novos conteúdos e oferece aos alunos exercícios para a aprendizagem. Nessa perspectiva, é responsabilidade do professor corrigir os erros que os estudantes cometem nas soluções das questões. O ambiente que dá suporte a uma investigação em sala de aula é denominado, por esses autores, de Cenário para Investigação. Um cenário para investigação, de acordo com Skovsmose (2000) constituise como

aquele que convida os alunos a formularem questões e procurarem explicações. $\mathrm{O}$ convite é simbolizado pelo "O que acontece se ... T" do professor. O aceite dos alunos ao convite é simbolizado por seus "Sim, o que acontece se ... T". Dessa forma, os alunos se envolvem no processo de exploração. O "Por que isto ...?" do professor representa um desafio e os "Sim, por que isto ... T" dos alunos indica que eles estão encarando o desafio e que estão procurando explicações (SKOVSMOSE, 2000, p. 6). 
DOI: http://dx.doi.org/10.33238/ReBECEM.2019.v.3.n.2.22629

Essa substituição de aulas tradicionais por cenários para investigação passa, obrigatoriamente, pela substituição de exercícios tradicionais por atividades investigativas ou exploratórias defendidas por Ponte (2004).

Assim, a criação de situações de aprendizagem pode levar os alunos a desenvolver atividades ricas e produtivas contribuindo para que o professor supere um dos problemas fundamentais de sua prática, a repetição de tarefas similares. "Uma boa estratégia de ensino normalmente é constituída por distintos tipos de tarefas" (PONTE, 2004, p.1). De acordo com Ponte (2004), há quatro categorias para as atividades desenvolvidas em sala de aula: Exercício, Problema, Exploração e Investigação. Estas categorias são determinadas por dois fatores: o grau de dificuldade (linha vertical) e a estrutura (linha horizontal).

Figura 1: As quatro categorias de atividades

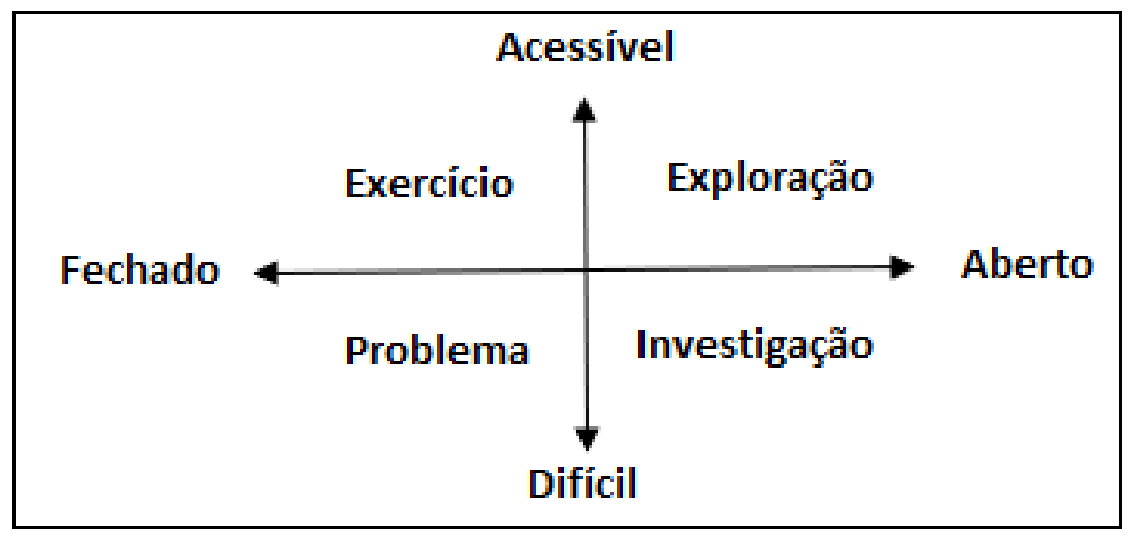

Fonte: (PONTE, 2004, p. 9, tradução nossa)

A estrutura, segundo Ponte (2004, p.8), varia entre os polos "aberto" e "fechado". Esse autor distingue a tarefa aberta da seguinte forma: "Uma tarefa fechada é aquela em que expressa claramente o que é dado e o que é pedido, e uma tarefa aberta é aquela que envolve um grau significativo de indeterminação no que é dado, no que é pedido ou em ambos". Neste texto utilizaremos o termo atividades investigativa-exploratórias para descrever exercícios de matemática com potencial para propiciar explorações e investigações que transcendam a matemática financeira propriamente dita.

Ponte (2004) ainda elaborou uma tabela esclarecedora sobre as características das tarefas e suas respectivas potencialidades: 
DOI: http://dx.doi.org/10.33238/ReBECEM.2019.v.3.n.2.22629

Quadro 1: Exemplos e potencialidades das atividades

\begin{tabular}{|l|l|l|}
\hline \multicolumn{1}{|c|}{$\begin{array}{c}\text { CARACTERÍSTICAS } \\
\text { DEAS TAREAS }\end{array}$} & \multicolumn{1}{|c|}{ EJEMPLOS } \\
\hline $\begin{array}{l}\text { Naturaleza más } \\
\text { cerrada }\end{array}$ & Ejercicios, problemas & $\begin{array}{l}\text { POTENCIALIDADES } \\
\text { Importantes para el desarrolo del racíocinio } \\
\text { una relación estrecha y rigurosa entre datos y } \\
\text { resultados. }\end{array}$ \\
\hline $\begin{array}{l}\text { Naturaleza más } \\
\text { accesible }\end{array}$ & $\begin{array}{l}\text { Exploraciones, } \\
\text { ejercicios }\end{array}$ & $\begin{array}{l}\text { Conceden al alumno un elevado grado de } \\
\text { exito y de desarrollo de la confianza en sí } \\
\text { mismo. }\end{array}$ \\
\hline $\begin{array}{l}\text { Naturaleza más } \\
\text { desafiante }\end{array}$ & $\begin{array}{l}\text { Investigaciones, } \\
\text { problemas }\end{array}$ & $\begin{array}{l}\text { Indispensables para que los alumnos vivan } \\
\text { una experiencia matemática efectiva. }\end{array}$ \\
\hline $\begin{array}{l}\text { Encuadradas en } \\
\text { contextos reales }\end{array}$ & $\begin{array}{l}\text { Tareas de aplicación } \\
\text { y de modelación }\end{array}$ & $\begin{array}{l}\text { Importantes para que el alumno se dé cuenta } \\
\text { del modo como se utilizan las matemáticas } \\
\text { en muchos contextos y para aprovechar su } \\
\text { conocimiento de estos contextos. }\end{array}$ \\
\hline $\begin{array}{l}\text { Formuladas en } \\
\text { contextos matemáticos }\end{array}$ & $\begin{array}{l}\text { Investigaciones, } \\
\text { problemas, } \\
\text { exploraciones. }\end{array}$ & $\begin{array}{l}\text { Permiten que el alumno se dé cuenta de } \\
\text { como se desarrola la actividad matemática de } \\
\text { los matemáticos profesionales. }\end{array}$ \\
\hline
\end{tabular}

Fonte: (PONTE, 2004, p.11)

Para Skovsmose, as questões de matemática podem fazer referência a três categorias: matemática pura, semi-realidade e ao mundo real. A categoria da matemática pura abrange as questões construídas somente por elementos matemáticos, por exemplo, efetue $1 / 4+2 / 3$ ou resolva a equação $2 x+3=9$. Para exemplificar, uma questão de semirealidade exemplificada por Skovsmose:

Um feirante A vende maçãs a $0,85 €$ o kg. Por sua vez, o feirante B vende 1,2 $\operatorname{kg}$ por $1,00 €$.

(a) Que feirante vende mais barato?

(b) Qual é a diferença entre os preços cobrados pelos dois feirantes por $15 \mathrm{~kg}$ de maçãs? (SKOVSMOSE, 2000, p.8)

Essa questão é enquadrada na semi-realidade porque, mesmo estando vinculada a realidade, é uma questão artificial que não foi confeccionada a partir de uma investigação empírica. As questões com referências a realidade são formadas por situações verdadeiras, reais. Desse modo, segundo Skovsmose (2000), há seis diferentes abordagens. 
DOI: http://dx.doi.org/10.33238/ReBECEM.2019.v.3.n.2.22629

Quadro 2: Exercícios e cenários para a investigação

\begin{tabular}{|l|c|c|}
\hline & Exercícios & Cenário para Investigação \\
\hline Referências à matemática pura & $(1)$ & $(2)$ \\
\hline Referências à semi-realidade & $(3)$ & $(4)$ \\
\hline Referências à realidade & $(5)$ & $(6)$ \\
\hline
\end{tabular}

Fonte: (SKOVSMOSE, 2000)

\section{A investigação realizada}

Sob a influência do grupo de matemática financeira do Projeto Fundão/UFRJ e do Pesquisa de Ponta/UFJF, foi criado um grupo de estudos em Educação Financeira Escolar no IFRJ-Campus Paracambi.

Esse grupo atuou em pesquisa e, principalmente, em extensão, visitando escolas e divulgando os estudos de novas ideias para a abordagem da matemática financeira. $\mathrm{O}$ grupo se dedicou a questões tradicionais da matemática financeira, utilizando o deslocamento do dinheiro no tempo como as desenvolvidas pelo grupo coordenado por Nasser (2010), e questões que rompem a barreira da matemática financeira tradicional, principalmente ligadas ao consumo e a tomada de decisão, inspirada nas pesquisas de Kistemann Jr. Durante os três anos em que atuou, o grupo criou algumas atividades destinadas a ampliar a abordagem da matemática financeira na sala de aula e oferecer aos professores exemplos de atividades investigativa-exploratórias.

Um teste contendo três possíveis atividades investigativa-exploratórias foi formulado e aplicado a uma pequena turma (7 estudantes) de alunos do $8^{\circ}$ período da licenciatura em matemática de Paracambi, no início do curso de matemática financeira. Eles fizeram essas atividades individualmente, podendo utilizar a calculadora e consultar o caderno. Até momento da aplicação dessas atividades, havia estudado apenas porcentagem, conteúdo inicial da disciplina e essencial para a resolução das questões. As questões propostas nas aulas que antecederam essa atividade poderiam ser classificadoas como questões tradicionais, classificados por Ponte (2004) como exercícios e problemas e por Skovsmose (2000) como exercícios de matemática pura e de semi-realidade.

A primeira questão da atividade (Figura 2) apresenta uma situação real retirada de um gigante magazine brasileiro, podendo ser enquadrada como um exercício com referência a realidade, número 5 na tabela de Skovsmose (Quadro 2). Por outro lado, de acordo com Ponte, esta quatão poderia ser enquadrada como um problema fechado, pois apresenta uma única solução (Figura 1). 
Figura 2: Questão 1

Questão 1 - Observe o anúncio a seguir e desenvolva as questões propostas

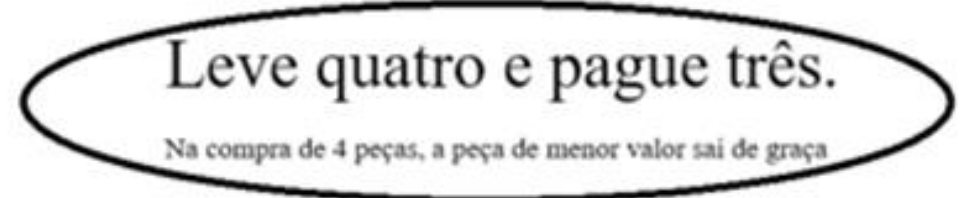

Anúncios desse tipo são comuns nos diversos estabelecimentos do pais. Baseando-se no anúncio acima, resolva os itens a seguir.

a) Descreva a situação em que o cliente pode obter o maior percentual de desconto.

b) Calcule o percentual máximo de desconto praticado pelo anunciante.

Fonte: Autores

A questão 2 promove um rompimento em uma característica do paradigma do exercício, a existência de solução única. Há diversas justificativas viáveis para a desproporcionalidade dos preços e os impactos na tomada decisão serão distintos de cidação para cidadão, de indivíduo consumidor para indivíduo consumidor. O problema apresentado na questão 2 pode ser classificado como investigativo ou exploratório (Quadro 1) fazendo referência a realidade.

Figura 3: Questão 2

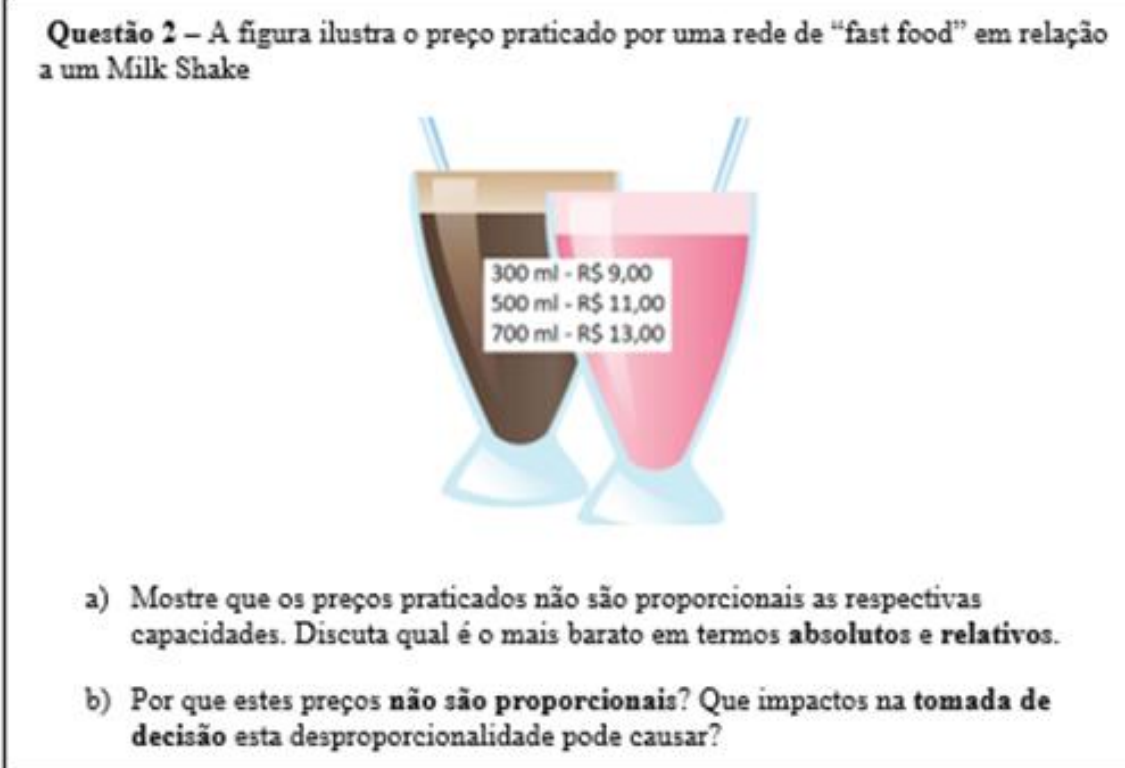

Fonte: Autores

A questão 3 apresenta um problema fechado relacionado a uma situação real. Tem um viés interdisciplinar relacionando a matemática financeira ao direito do consumidor. 
DOI: http://dx.doi.org/10.33238/ReBECEM.2019.v.3.n.2.22629

Figura 4: Questão 3

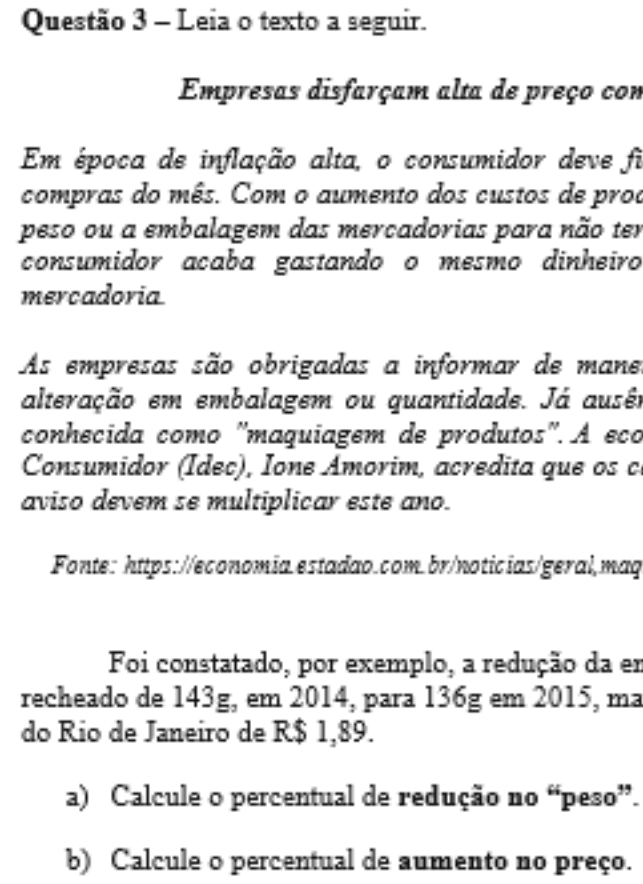
mercadoria. aviso devem se multiplicay este ano. do Rio de Janeiro de $\mathrm{R} \$ 1,89$.

a) Calcule o percentual de redução no "peso".

b) Calcule o percentual de aumento no preço.

Em época de inflação alta, o consumidor deve ficar ainda mais atento ao fazer as compras do més. Com o aumento dos custos de produção, algumas empresas reduzem o peso ou a embalagem das mercadorias para não ter de aumentar o preço. Na prática, o consumidor acaba gastando o mesmo dinheiro por uma quantidade menor de

As empresas são obrigadas a informar de maneira clava ao consumidor qualquer alteração em embalagem ou quantidade. Já auséncia do aviso é uma prática ilegal conhecida como "maquiagem de produtos". A economista do Instituto de Defesa do Consumidor (Idec). Ione Amorim, acredita que os casos de redução de embalagens sem

Fonte: https://economiz estadao com brinoticias/geral, maquiagem-de-produtos-tende-a-aumentar-emepoca-de-ivflacao-aita, 1717404

Foi constatado, por exemplo, a redução da embalagem de um famoso biscoito recheado de $143 \mathrm{~g}$, em 2014 , para $136 \mathrm{~g}$ em 2015 , mantendo seu preço médio na cidade

Fonte: Autores

O objetivo dessa atividade não era investigar o desempenho matemático dos licenciandos, mas analisar os argumentos e as percepções após a resolução das questões. Para ajudar nessa tarefa, foi criada a quarta questão que solicitava aos alunos para avaliarem a utilização das atividades investigativa-exploratórias na sala de aula.

\section{As soluções dos licenciandos}

Neste artigo, serão analisadas as soluções da questão 2 e as avaliações das atividades proposta na questão 4. Identificaremos os estudantes pelas letras de "A" a "G".

Questão 2 - A proporcionalidade do preço do milk shake

As soluções apresentadas no item a dessa questão foram corretas. Todos alunos compreenderam a não proporcionalidade dos produtos em relação aos seus respectivos preços, identificaram o produto com maior volume como o mais caro em termos absolutos e mais barato em termos relativos.

$\mathrm{O}$ item b, no entanto, promoveu respostas interessantes. Os estudantes A, C e E concluíram que o impacto da desproporcionalidade na tomada de decisão é "comprar o mais caro". O estudante D apontou que a empresa lucra mais ao vender o produto com a menor embalagem e o estudante $\mathrm{G}$ acredita que se os preços fossem proporcionais os clientes ficariam insatisfeitos (ele não justificou o motivo desta conclusão). 


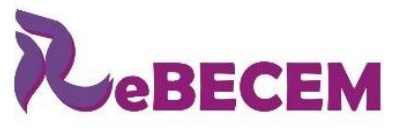

\section{Revista Brasileira de Educação em \\ Ciências e Educação Matemática}

ISSN 2594-9179

$\mathrm{O}(\mathrm{A})$ estudante $\mathrm{F}$ observou que essa rede de fast food faz pesquisa de mercado para determinar o preço dos produtos e que identifica a existência de um gasto constante, "mais ou menos" idêntico na produção dos produtos.

Figura 5: Solução do(a) estudante $F$

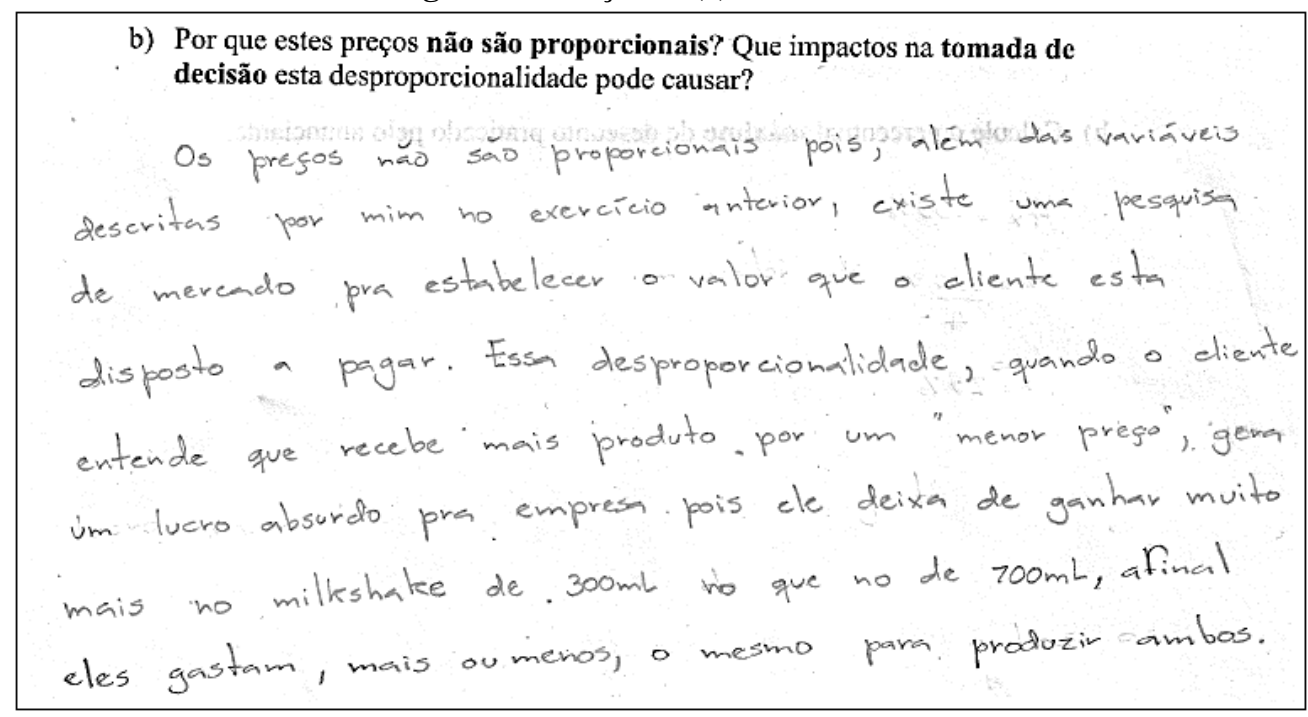

Fonte: Autores

Um interessante desdobramento a partir da solução de "F" é que a função que determina os preços desse produto está mais relacionada a uma função afim com o coeficiente linear diferente de zero. E, a partir daí o professor pode por exemplo discutir as relações entre as funções afins e a proporcionalidade.

$\mathrm{O}$ (a) estudante "E" observa um possível "superfaturamento" do preço do milk shake menor para que "não o escolham com frequência" ou para aumentar o lucro com os que os escolhem. No entanto, "E" acredita que a maioria dos consumidores não irá escolher o mais barato em termos relativos e que o impacto maior será dado pelo preço absoluto. Esse(a) estudante escreve: "fiquei na dúvida sobre a real intenção do comércio".

Figura 6: Solução da questão 2 do(a) estudante $\mathrm{F}$

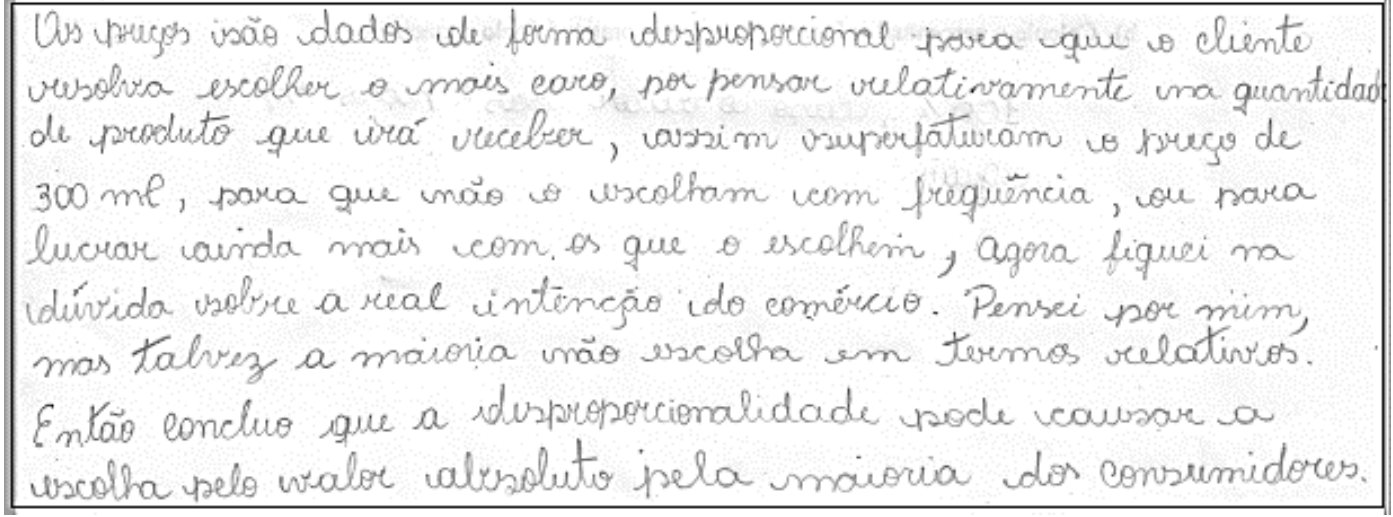

Fonte: Autores 
DOI: http://dx.doi.org/10.33238/ReBECEM.2019.v.3.n.2.22629

A questão 4 - A avaliação dos licenciandos

Nessa questão, os alunos foram convidados a apontar pontos positivos e negativos das atividades propostas. Os estudantes "A", "D", "E" e " $F$ " elogiaram as atividades por fazer conexão com a realidade. Segundo "E", "estas questões ajudam a desenvolver ferramentas não pré-estabelecidas como geralmente ocorre nas questões comuns". O(a) estudante $\mathrm{F}$ aponta como ponto negativo o texto anterior a questão 3 por não ajudar na solução do problema (veja figura 7). Dentro da cultura relacionada ao paradigma do exercício, a crítica faz todo o sentido, entretanto, em uma atividade investigativaexploratória, talvez textos "contextualizadores" como esse devem ser utilizados, pois a estas atividades estão presentes objetivos que vão muito além da resolução das questões.

Figura 7: Solução da questão 4 do(a) estudante F

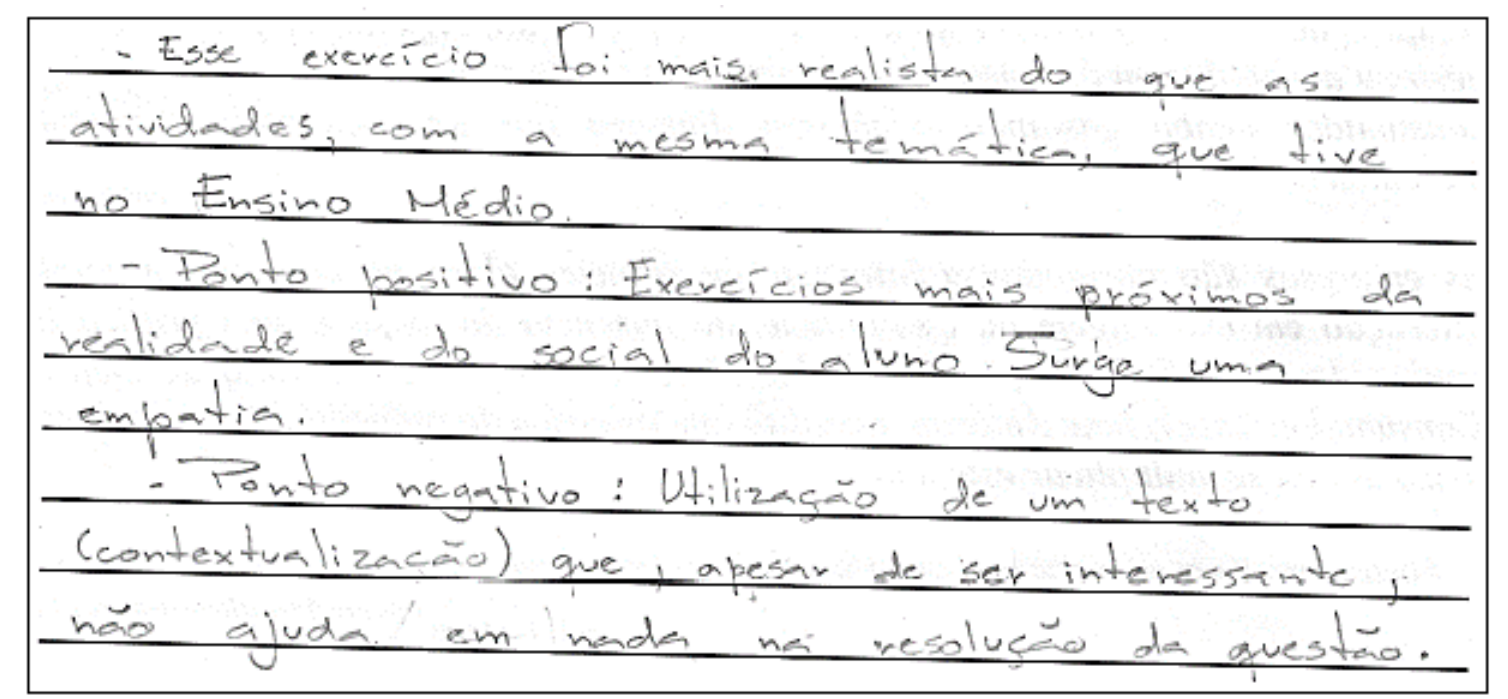

Fonte: Autores

$\mathrm{O}(\mathrm{A})$ estudante $\mathrm{B}$, atividades como essa podem promover uma maior conscientização dos alunos enquanto consumidores, oferecendo a eles mais ferramentas para se precaver de "abusos do comércio". "B" percebe que os exercícios de matemática financeira tradicionais são voltados para "cálculos e a obtenção de resultados". 


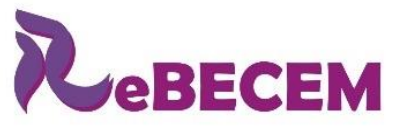

DOI: http://dx.doi.org/10.33238/ReBECEM.2019.v.3.n.2.22629

Figura 8: Solução da questão 4 do(a) estudante B
Revista Brasileira de Educação em

\section{Ciências e Educação Matemático}

ISSN 2594-9179

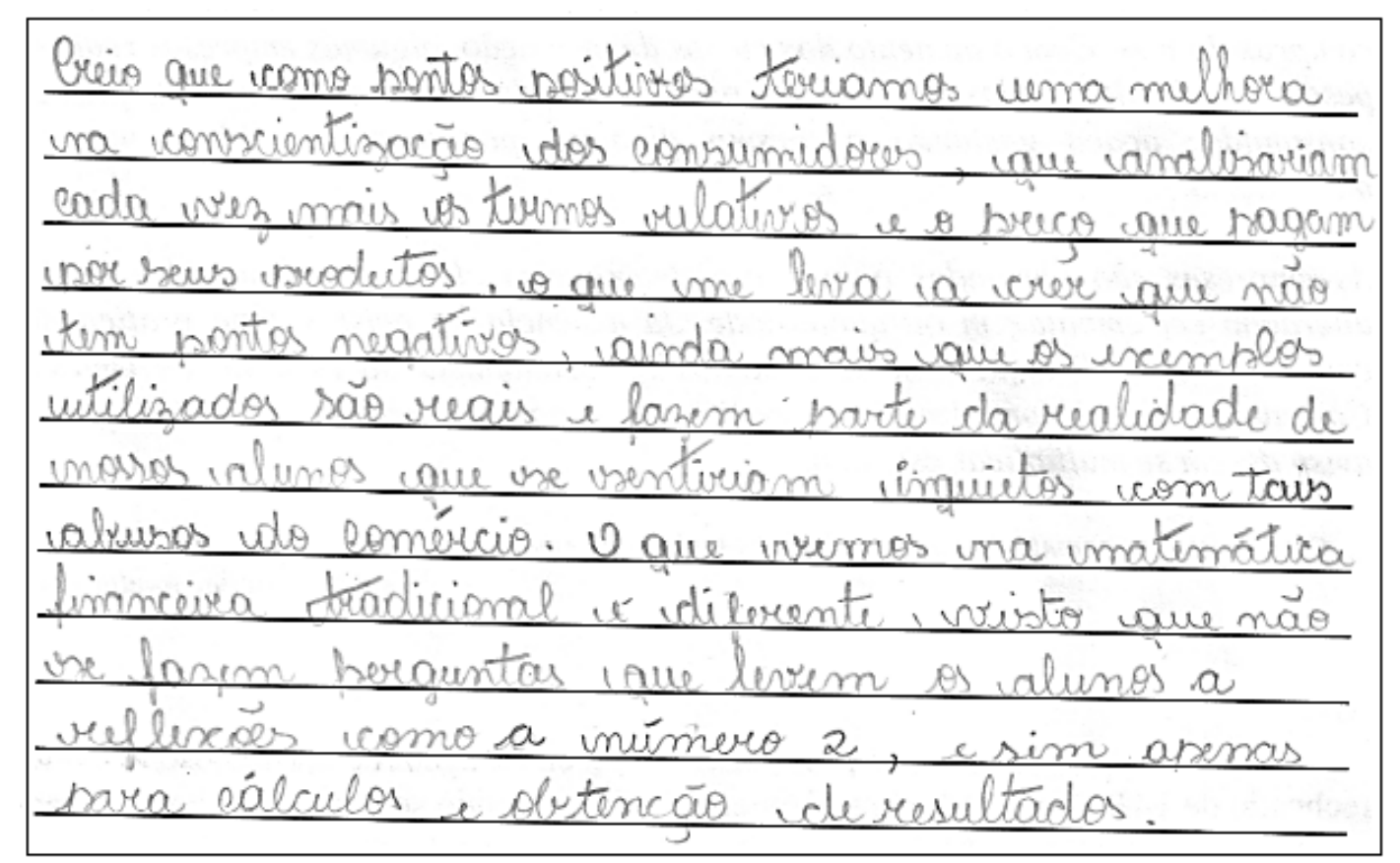

Fonte: Autores

Para o(a) estudante $\mathrm{C}$, ficou evidente o contraste dessas atividades com as tradicionais que não buscam aplicar a matemática em situações do cotidiano. "C" faz a crítica mais interessante (em nosso ponto de vista), pois segundo ele(a) esta atividade "fica devendo em colocar o aluno sempre no papel de consumidor e nunca de empreendedor".

Figura 9: Solução da questão 4 do(a) estudante C

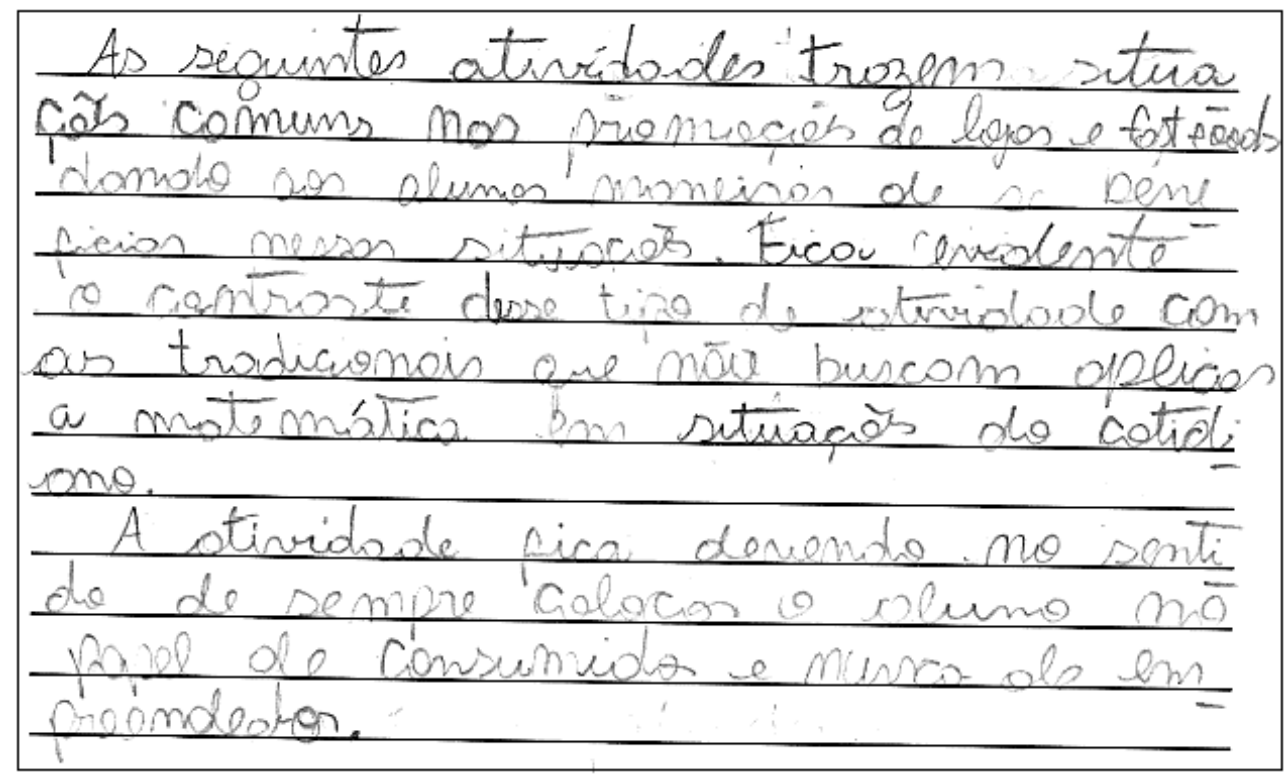

Fonte: Autores 


\section{Considerações finais}

Embora em muitas salas de aulas pelo Brasil já ocorram projetos envolvendo Educação Financeira, muitas escolas poderiam de forma inter e transdisciplinar envolver seus estudantes em cenários para investigação com temas financeiro-econômicos com a participação das diversas disciplinas e indo além da sala de aula de Matemática e de práticas algorítimicas de Matemática Financeira.

O educador matemático inserido em uma perspectiva crítica deve refletir sobre perguntas que direcionam suas práxis enquanto professor de matemática: "o que ensinar?”, “por que ensinar isso?”, “por que não ensinar aquilo?”, “como ensinar para uma melhor aprendizagem?" e “o que seria uma melhor aprendizagem?”. À luz da Educação matemática Crítica que nos embasamos neste artigo, o professor de matemática tem um importante papel social, de legitimador de desigualdades ou de, nas palavras do educador matemático Luiz Felipe Lins, um professor “oportunizador” de sonhos.

Explorar a capacidade argumentativa dos estudantes, promover reflexão sobre o consumo, as multinacionais e suas estratégias de venda, suscitando dúvidas como as manifestadas por "E" compõem características de um ambiente investigativo/exploratório conforme Ponte (2004) e um cenário para investigação, segundo Skovsmose (2000). Assim, quando um estudante questiona o papel dos alunos como indivíduosconsumidores, e não como investidores, a educação matemática se torna formadora e transformadora. Formadora de estudantes mais críticos enquanto consumidores e mais atuantes enquanto cidadãos.

Por fim, a Educação Financeira, alicerçada por conhecimentos de Matemática Financeira, Economia, Sociologia, Marketing e Comportamento do Consumidor é a tendência que está crecendo e que vai influenciar a vida dos indivíduos consumidores independente de suas idades. Não é mais um projeto futuro, mas uma realidade.

\section{Referências}

ALMEIDA, R. M. O movimento das pesquisas em educação matemática financeira escolar de 1999 a 2015. 2015. Dissertação (Mestrado Profissional em Educação Matemática) - Instituto de Ciências Exatas, Universidade Federaal de Juiz de Fora, Juiz de Fora, 2015.

ALRO, H; SKOVSMOSE, O. Diálogo e aprendizagem em educação matemática. 2. ed. Belo Horizonte: Autêntica, 2010.

BARBOSA, J. C. Modelagem na Educação Matemática: contribuições para o debate teórico. In: REUNIÃO ANUAL DA ANPED, 24, 2001, Caxambu. Anais... Caxambu, 2001. p. 1-15. 
DOI: http://dx.doi.org/10.33238/ReBECEM.2019.v.3.n.2.22629

BAUMAN, Z. A riqueza de poucos beneficia a todos nós? 1. ed. Rio de Janeiro: Zahar, 2015.

D'AMBROSIO, Ubiratan. Educação para uma sociedade em transição. 3.ed. São Paulo: Editora Livraria da Física, 2016

KISTEMANN JR., M. A. Por uma educaçâo matemática para além do capital e com justiça social. In: LESTÓN, P. (org.). Acta Latinoamericana de Matemática Educativa. 5. ed. México, DF: Comité Latinoamericano de Matemática Educativa, 2014. p. 145-152.

KISTEMANN JR., M. A.; CAMPOS, R. Sobre a produçâo de significados e a tomada de decisâo de indivíduos-consumidores. In: FLORES, R. (org.). Acta Latinoamericana de Matemática Educativa. Edição. México, DF: Comité Latinoamericano de Matemática Educativa, 2014a. p. 999-1006.

KISTEMANN JR, M. A.; CAMPOS, R. Enquanto isso na Sociedade de Consumo LíquidoModerna: a produção de significados e a tomada de decisão de indivíduos-consumidores. Boletim de Educação Matemática, Joinvilhe (SC), v. 28, n. 50, p.21-40, outubro. 2014b.

LIMA, C. B.; SÁ, I. P. Matemática financeira no ensino fundamental. Revista Eletrônica TECCEN, Vassouras - RJ, v. 3, n. 1, p. 34-43, abr. 2010.

LOERWALD, D.; STEMMANN, A. Behavioral Finance and Financial Literacy: Educational Implications of Biases in Financial Decision Making. In: APREA. C. et al. (org) International Handbook of Financial Literacy. 1. ed. Singapore: Springer, 2016. p. 25-38.

MUNIZ, Jr, I.; JURKIEWICZ, S. Representações temporais e o valor do dinheiro no tempo: conexões entre a Educação Financeira e o Ensino de Matemática. Boletim Online de Educação Matemática, Santa Catarina. v. 4, n. 7, p. 116-138. 2016.

NASSER, L. (coord.). Matemática Financeira na Escola Básica: uma abordagem prática e visual. 1. ed. Rio de Janeiro. Rio de Janeiro: IM-UFRJ, 2010.

PONTE, J. P. Problemas e investigaciones en la actividad matemática de los alumnos. In: J. GIMÉNEZ, J.; SANTOS, L.; PONTE, J. P. (org.). La actividad matemática en el aula. 1. ed Barcelona: Graó, 2004. p. 25-34.

SILVA, A. B. B. Mentes consumistas: do consumismo à compulsão por compras. 1. ed. São Paulo: Globo, 2014.

SKOVSMOSE, O. Cenários para investigação. Bolema, Rio Claro, v. 13, n. 14, p. 66-91, agosto, 2000

SKOVSMOSE, O. Educação Matemática Crítica: a questão da democracia. 1 ed. Editora Papirus: Campinas, 2013

SKOVSMOSE, O. Um convite à educação matemática crítica.1 ed. Campinas: Papirus, 2014.

Recebido em: 16 de junho de 2019.

Aceito em: 01 de agosto de 2019. 